\title{
Anomalias das temperaturas máximas do ar na cidade de Patos, Paraíba
}

Anomalies of maximum air temperatures in the city of Patos, Paraíba

MARQUES ${ }^{1}$, G. B.; SILVA¹, T. S.; LIMA¹, E. R. R.; MOURA², M. O.

guibm@hotmail.com

\begin{abstract}
Resumo
Este artigo possui o objetivo de analisar a periodicidade das anomalias identificadas na série das temperaturas máximas do ar da cidade de Patos no período de 2010 a 2014. As anomalias foram classificadas de acordo com a sua duração (comprimento) e sua gravidade térmica (amplitude e intensidade). A princípio, estabeleceu-se anomalias com duração de 3 dias, 4 dias e $\geq 5$ dias, as quais foram classificadas segundo à sua amplitude (Alta, Moderada e Baixa), assim como à sua intensidade térmica (Forte, Moderado e Fraco). Um total de 110 anomalias fora identificado. Desse valor, 52 anomalias encontra-se na faixa de duração $\geq 5$ dias. Os valores máximos de amplitude e intensidade térmica da série foram encontrados para as anomalias com duração $\geq 5$ dias.
\end{abstract}

Palavras-chave: temperaturas extremas do ar, variabilidade, períodos térmicos extremos.

\begin{abstract}
This paper has the purpose of analyzing the frequency of anomalies identified in the series of maximum temperatures of the air in the city of Patos in the period 2010 - 2014. The anomalies were classified according to its duration (length) and its thermal gravity (amplitude and intensity). At first, it was settled that 3 days anomalies, 4 days and $\geq 5$ days, which were classified according to their range (high, moderate and low), as well as to its thermal intensity (strong, moderate and weak). A total of 110 anomalies were identified. Of this amount, 52 anomalies are in the range of length of $\geq 5$ days. The maximum values of thermal amplitude and intensity were found for anomalies with duration of $\geq 5$ days.
\end{abstract}

Keywords: air extreme temperature, variability, extreme thermal periods.

\section{INTRODUÇÃO}

A cidade de Patos localiza-se na Mesorregião do Sertão, na porção oeste do Estado da Paraíba, à sotavento da Borborema central (mapa 1). Essa região é marcada pelo clima semiárido, quente e seco que registram temperaturas médias anuais superiores a $24^{\circ} \mathrm{C}$, porém, com um clima semiúmido nas áreas de serras. A partir da cidade de Patos se inicia a depressão sertaneja, que geomorfologicamente apresenta uma superfície aplainada, apresentando uma altitude em torno de $250 \mathrm{~m}$, com a presença de morros testemunhos isolados; os inselbergs.

A precipitação anual na cidade de Patos varia entre $700,0 \mathrm{~mm}$ e $750,50 \mathrm{~mm}$ e se caracteriza por uma sua irregularidade temporal e espacial. A estação chuvosa ocorre entre fevereiro e maio ocasionada pela atuação da Zona de Convergência Intertropical. Segundo Cavalcante (2008) "o território da cidade de Patos está inserido climaticamente no domínio semiárido subequatorial e tropical que constitui o polígono das secas", sendo assim em eventos de seca, em uma escala temporal de 10 anos, ao menos três anos são secos nessa região.

\footnotetext{
${ }^{1}$ Guilherme Barroca Marques, Tatiana dos Santos Silva, Erlânio Rurik Ribeiro de Lima, Graduandos em Geografia, Laboratório de Climatologia Geográfica, Universidade Federal da Paraíba, João Pessoa-PB, Brasil

${ }^{2}$ Marcelo de Oliveira Moura, Professor Adjunto, Laboratório de Climatologia Geográfica, Universidade Federal da Paraíba, PB, Brasil
} 
O presente artigo tem como objetivo geral identificar e classificar as anomalias das temperaturas máximas na cidade de Patos, no período de 2010 a 2014 por meio de análises anuais, mensais e sazonais. Essas análises revelarão os períodos de calor forte já registrados na cidade.

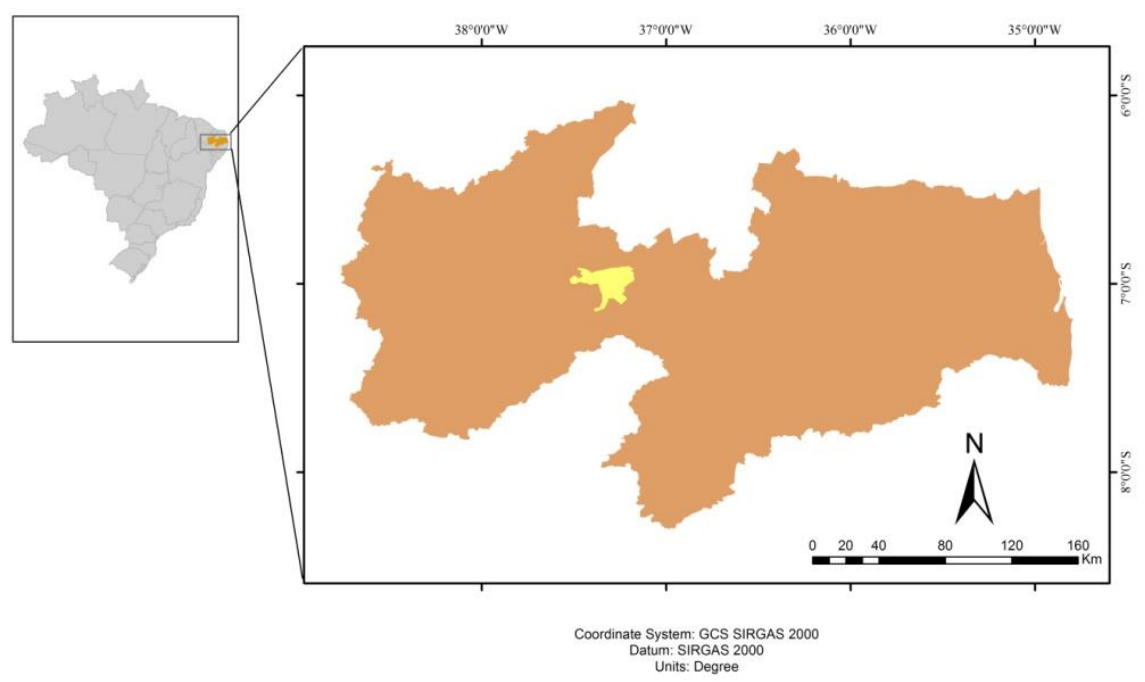

Mapa 1 -Localização da cidade de Patos, Paraíba. Organização : Guilherme Barroca Marques

\section{METODOLOGIA}

Realizou-se um estudo exploratório da série diária das temperaturas máximas do ar do período de 2010 a 2014. Os dados foram obtidos no Banco de Dados Meteorológicos para Ensino e Pesquisa - BDMEP do Instituto Nacional de Meteorologia - INMET (BDMET/INMET, 2015) da Estação Meteorológica de Patos. A identificação das anomalias das temperaturas máximas do ar ou anomalias térmicas positivas ocorreu de acordo com as orientações de Rusticucci e Vargas (2001), Rusticucci e Barrucand (2001), Jiménez, Gil e Herdera (2005), Firpo (2008) e Moura (2015).

A caracterização e a identificação das anomalias das temperaturas máximas da série foram desenvolvidas através das seguintes etapas:

1) Confecção de tabelas no ambiente do Microsoft Excel 2010 (Microsoft Corporation), no formato de planilhas eletrônicas, para a sistematização da base de dados e verificação de falhas da série, além da tabulação dos dados em dia/mês;

2) Identificação das anomalias, por meio do cálculo da normal climatológica diária das temperaturas máximas do ar, através do emprego da média aritmética, para cada dia do ano, de todas as temperaturas diárias registradas no período de 2010 a 2014. Considerou-se como anomalia térmica a persistência de três ou mais dias consecutivos e ininterruptos de anomalias. 
Esse procedimento serviu para determinar o comprimento, ou seja, a duração das anomalias, as quais foram classificadas em três categorias: anomalias de 3 dias, de 4 dias e anomalias $\geq 5$ dias;

3) Classificação das anomalias quanto à gravidade térmica (amplitude e intensidade). Para a obtenção da amplitude térmica, calculou-se a diferença entre o maior e o menor valor de anomalia de cada comprimento, isto é, o intervalo das anomalias $(\Delta \mathrm{A})$. Com esse procedimento, também foi possível identificar a intensidade da anomalia, ou seja, o pico térmico do período anômalo, portanto, o pico térmico representa o maior valor de anomalia térmica presente em cada comprimento;

4) Para a classificação da gravidade térmica das anomalias foi aplicada a técnica estatística dos percentis (TRIOLA, 2008) à série das amplitudes e intensidades das anomalias, com o intuito de agrupar em categorias e classes de gravidade os valores de amplitude e intensidade da série, conforme mostra o quadro 1.

\begin{tabular}{|c|c|c|c|}
\hline \multirow{5}{*}{ 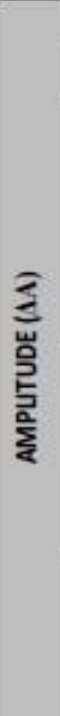 } & \multicolumn{3}{|c|}{ ANOMALIAS TERMICAS } \\
\hline & Categoria & Classe & Descriçāo \\
\hline & 1 & $\begin{array}{c}\text { BAIXA } \\
(\mathrm{B}) \\
\left(\mathrm{O}^{\circ}, 2^{\circ} \mathrm{C}+0,5^{\circ} \mathrm{C}\right) \\
\left(P_{1}\right) \underset{\left(P_{5}\right)}{(}\end{array}$ & $\begin{array}{c}P 5=0,5^{\circ} \mathrm{C} \\
5 \% \text { (95\%) dos valores de } \\
\text { amplitude estâo abaixo } \\
\text { (acima) de } 0,5^{\circ} \mathrm{C}\end{array}$ \\
\hline & 2 & 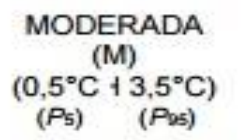 & $\begin{array}{c}90 \% \text { dos valores de } \\
\text { amplitude se situam entre } \\
P_{5 \text { s }} P_{56}\end{array}$ \\
\hline & 3 & $\begin{array}{c}\text { ALTA } \\
\text { (A) } \\
\left(3,5^{\circ} \mathrm{C}+3,7^{\circ} \mathrm{C}\right) \\
\left(P_{25)}\right)\left(P_{00}\right)\end{array}$ & $\begin{array}{c}P_{v 5}=3,5^{\circ} \mathrm{C} \\
95 \%(5 \%) \text { dos valores de } \\
\text { amplitude estấ abaixo } \\
\text { (acima) de } 3,7^{\circ} \mathrm{C}\end{array}$ \\
\hline \multirow{3}{*}{ 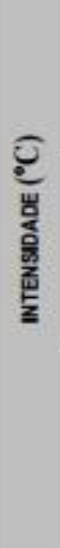 } & $\begin{array}{l}\text { PERIODO DE } \\
\text { CALOR } \\
\text { FRACO }\end{array}$ & $\begin{array}{c}\text { FRACO } \\
(\mathrm{FC}) \\
\left(0,4^{\circ} \mathrm{C}+0,7^{\circ} \mathrm{C}\right) \\
\left(\mathrm{P}_{7}\right) \quad\left(\mathrm{P}_{\mathrm{s}}\right)\end{array}$ & $\begin{array}{c}P 5=0,7^{\circ} \mathrm{C} \\
5 \% \text { (95\%) dos valores de } \\
\text { intensidade estấo abaixo } \\
\text { (acima) de } 0,7^{\circ} \mathrm{C}\end{array}$ \\
\hline & $\begin{array}{l}\text { PERIODO DE } \\
\text { CALOR } \\
\text { MODERADO }\end{array}$ & $\begin{array}{l}\text { MODERADA } \\
(M) \\
\left(0,7^{\circ} \mathrm{C}+4,0^{\circ} \mathrm{C}\right) \\
\left(P_{5}\right) \quad\left(P_{05}\right)\end{array}$ & $\begin{array}{c}90 \% \text { dos valores de } \\
\text { intensidade se situam entre } \\
\text { P5 e P95 }\end{array}$ \\
\hline & $\begin{array}{l}\text { PERIODO DE } \\
\text { CALOR } \\
\text { FORTE }\end{array}$ & $\begin{array}{c}\text { FORTE } \\
(\text { FT) } \\
\left(4,0^{\circ} \mathrm{C}+4,2^{\circ} \mathrm{C}\right) \\
\left(P_{05}\right) \quad\left(P_{509}\right)\end{array}$ & $\begin{array}{c}\text { Pass } 4,0^{\circ} \mathrm{C} \text {; } \\
95 \%(5 \%) \text { dos valores de } \\
\text { intensidade estấo abaixo } \\
\text { (acima) de } 4,2^{\circ} \mathrm{C}\end{array}$ \\
\hline
\end{tabular}

Quadro 1- Proposta de classificação da gravidade das anomalias das temperaturas máximas do ar. Fonte: Estação 3. RESULTADOS E DISCUSSÃO Meteorológica de Patos/INMET, 2015. Organização: autores. 
Registrou-se 110 anomalias térmicas positivas do no período de 2010 a 2014, sendo 38 anomalias com duração de 3 dias (35\% das ocorrências), 20 anomalias de 4 dias (18\% das ocorrência) e 52 são anomalias $\geq 5$ dias (47\% das ocorrência). A respeito das classificações das anomalias, no que tange à gravidade térmica (amplitude e intensidade), pelo viés estatístico estabelecido - análise dos percentis - os dados apresentam-se da seguinte forma: amplitude ( $89 \%$ na classe Moderada, 5\% na classe Baixo e 6\% na classe Alto ) e intensidade ( $93 \%$ na classe Moderado, 5\% na classe Forte e 2\% na classe Fraco).

A tendência das anomalias $\geq 5$ dias na cidade de Patos serem superiores aos demais comprimentos ou duração das anomalias foi também detectada por Moura (2015) para a cidade de Fortaleza, com 52,4\% dos registros de anomalias, e por Cavalcante e Moura (2015) para a cidade de João Pessoa, com $54 \%$ dos registros.

\section{1 - Análise quantitativa anual das anomalias das temperaturas máximas do ar}

As ocorrências anuais das anomalias no período de 2010 a 2014 na cidade de Patos, representadas no gráfico 1, evidenciam uma elevada variabilidade interanual. Nota-se uma variação entre os três tipos de comprimento das anomalias, anomalias $\geq 5$ dias possuem maior destaque. $\mathrm{O}$ ano de 2013 apresenta-se com os maiores registros da série, com 17 anomalias positivas.

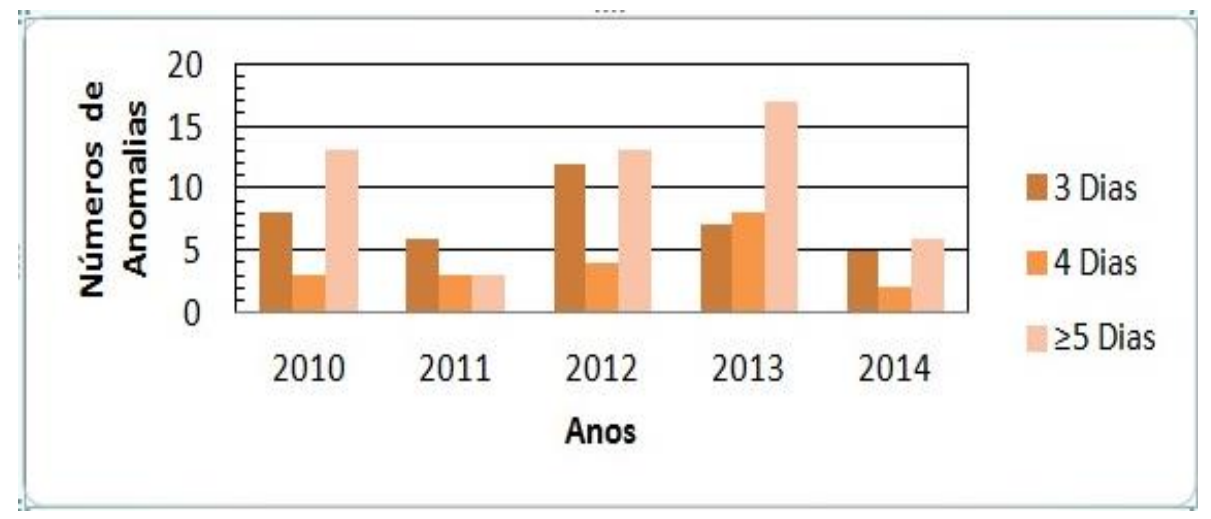

Gráfico 1 - Número de ocorrências anuais de anomalias extrema do ar em Patos- PB (2010-2014) Fonte: Estação Meteorológica de Patos/INMET, 2015.

Os anos de 2013 (32 anomalias) e de 2012 (29 anomalias) registram as maiores ocorrências de anomalias, já os anos de 2014 (13 anomalias) e de 2011 (12 anomalias) registram os menores quantitativos anuais. Com relação à variação interanual das classes de gravidade térmica para as anomalias de 3 dias, apenas o ano de 2014 não excedeu o número de 5 anomalias anuais. $\mathrm{O}$ maior número de anomalias foi registrado no ano de 2012 com 12 anomalias. No geral, as anomalias com duração de 3 dias caracterizaram-se por apresentar baixa gravidade térmica (relativo à amplitude e intensidade das anomalias) em todos os anos da série. 
No tocante a gravidade térmica das anomalias de 4 dias, o ano de 2013 possui o maior número de ocorrências de anomalias (8 anomalias), já em 2014 houve o menor registro de anomalia ( 2 anomalias). Contudo, a ocorrência de anomalias de 4 dias foram inferiores as anomalias de 3 dias. Já os registros de anomalias $\geq 5$ dias indicam uma frequência de ocorrência superior as ocorrências de anomalias de 3 e de 4 dias. O destaque é o ano de 2013, com registro de 17 anomalias com duração $\geq 5$ dias. Acerca da classificação de anomalias com duração $\geq 5$ dias em relação á gravidade térmica, isto é, o grau de amplitude e de intensidade, observou-se uma maior frequências dos eventos de amplitude alta e intensidade forte.

Os gráficos 2 e 3 mostram os totais de ocorrências anuais relacionadas à gravidades térmicas das anomalias com duração $\geq 5$ dias. O ano de 2013 registrou o maior número de ocorrências de gravidades térmicas de amplitude (16 ocorrências) e de intensidade (14 ocorrências) da série.

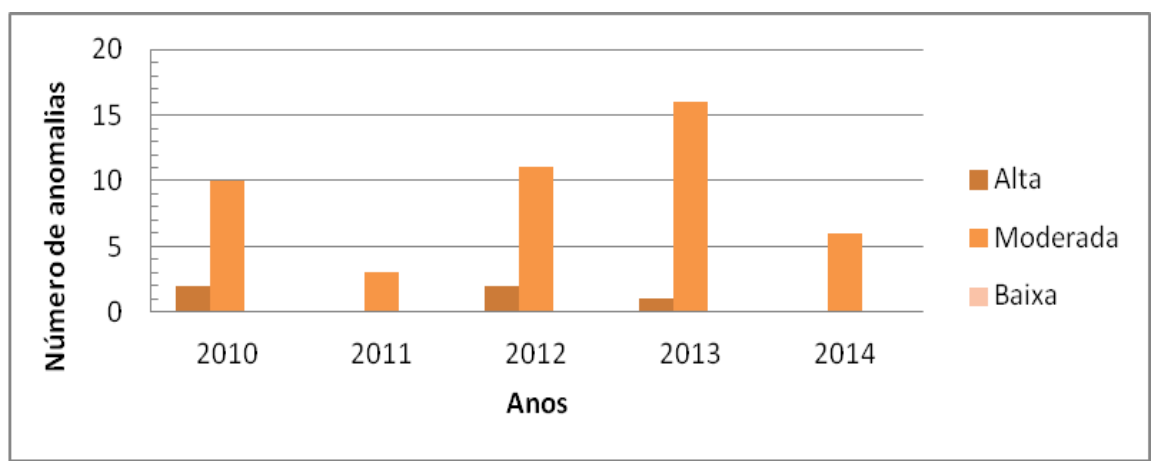

Gráfico 2 - Número de ocorrências anuais quanto à amplitude térmica das anomalias em Patos (2010 - 2014): duração $\geq 5$ dias. Fonte: Estação Meteorológica de Patos/INMET, 2015

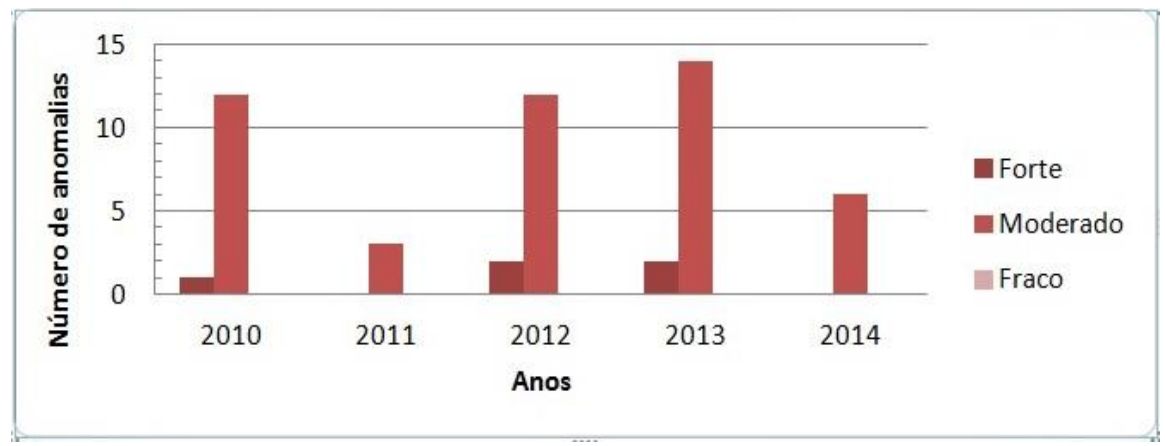

Gráfico 3 - Número de ocorrências anuais quanto à intensidade térmica das anomalias em Patos- PB (2010 - 2014): duração $\geq 5$ dia. Fonte: Estação Meteorológica de Patos/INMET, 2015

Ao analisar o número de ocorrências anuais de gravidade térmica de todas as anomalias com duração de 3, 4 e $\geq 5$ dias, constatou-se que os maiores valores quantitativos encontram-se nas classes moderadas de amplitude (89\% das ocorrências) e intensidade (93\% das ocorrências). Esses valores são superiores as ocorrências de amplitude baixa e alta, assim como as ocorrências de intensidade forte e fraca. Isso se deve às ordens percentílicas estabelecidas no agrupamento dos valores de amplitude e intensidade da série definidos na metodologia da pesquisa. 


\section{2 - Análise quantitativa sazonal e mensal das anomalias das temperaturas máximas do ar}

A distribuição dos meses do ano para o estabelecimento dos períodos sazonais das anomalias foi tomada com base na metodologia proposta por Silva (2007). Este autor subdividiu o estado da Paraíba em seis microrregiões pluviometricamente homogêneas, a saber: Litoral, Sertão, Agreste, Cariri/Curimataú, Sertão e Alto Sertão. A cidade de Patos está localizada na microrregião do Sertão, sua estação pré - estação chuvosa situa-se entre os meses de novembro a janeiro, a estação chuvosa durante os meses de fevereiro a maio e o período seco entre os meses de junho a outubro. A prancha 1 mostra a distribuição sazonal das anomalias quanto à sua duração, amplitude e intensidade térmica

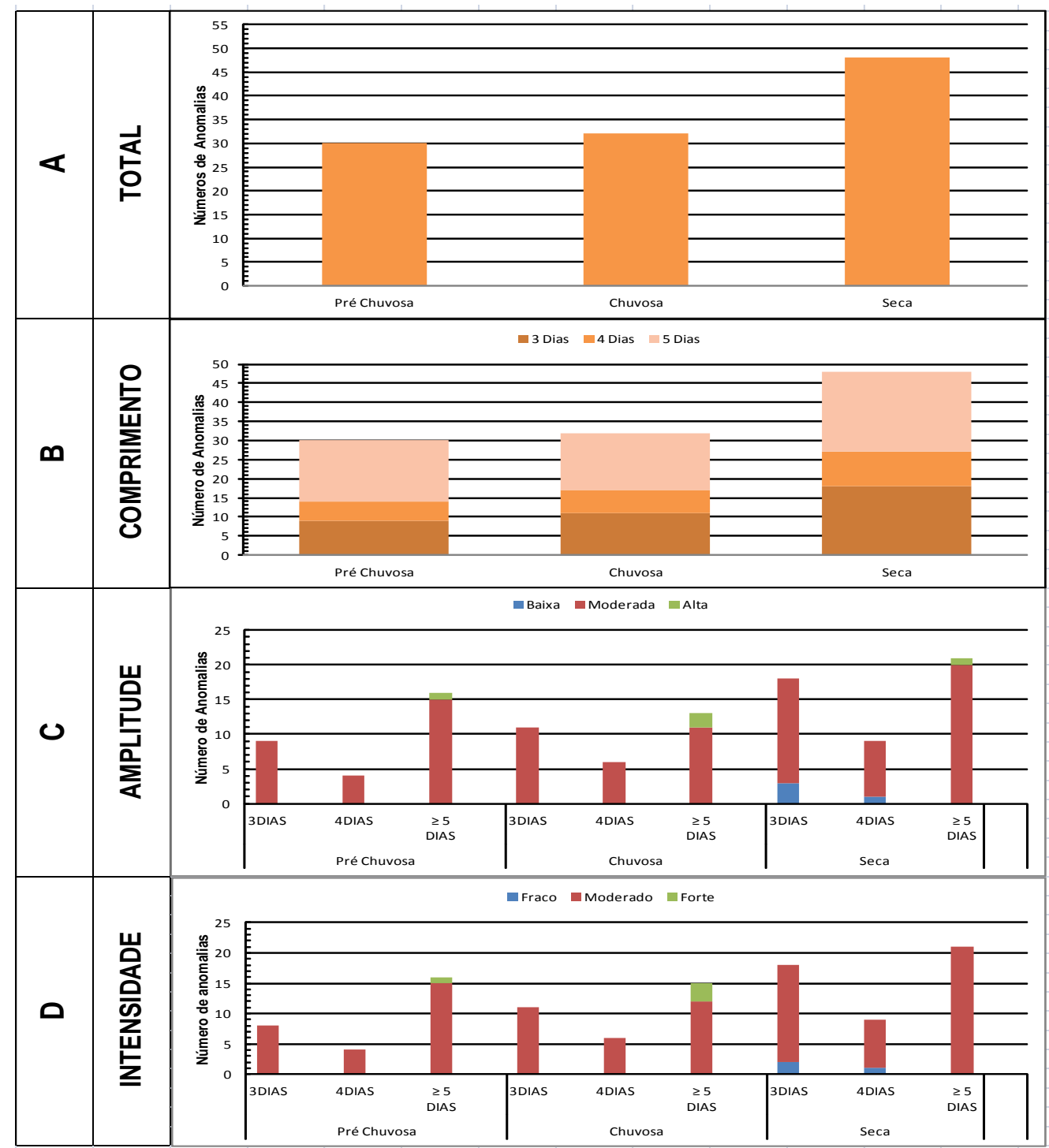

Prancha 1 - Distribuição quantitativa sazonal das anomalias das temperaturas máximas do ar em Patos (2010 - 2014). Fonte: Estação meteorológica de Patos/INMET, 2015

O gráfico A da prancha 1 mostra o total de ocorrências das anomalias por períodos sazonais. Destaca-se a estação seca com o maior número de anomalias (52 ocorrências), seguida da estação chuvosa (32 ocorrências) e da estação pré-chuvosa (30 ocorrências). 
O gráfico B refere-se à distribuição das anomalias por comprimento em cada estação. Anomalias de comprimento $\geq 5$ dias destacam-se com maior registro de ocorrências em todas estações, a estação seca possui o maior número de anomalias com 21 ocorrências.

Nos gráficos C e D, registram-se a distribuição das anomalias por classes de amplitude e intensidade térmica. A classe moderada apresenta-se com maior frequência em todos os períodos sazonais. Apesar disso, podemos observar que todos os períodos de calor forte e de amplitude alta da série foram registrados por anomalias com duração $\geq 5$ dias.

A distribuição mensal das anomalias representada no gráfico 4, aponta fevereiro como o mês de maior ocorrência de anomalias, seguido dos meses de outubro, novembro e dezembro. Logo, podemos afirmar que as ocorrências de anomalias térmicas concentram-se entre os meses correspondentes ao fim da estação seca, além dos meses da estação pré-chuvosa e dos meses do início da estação chuvosa.

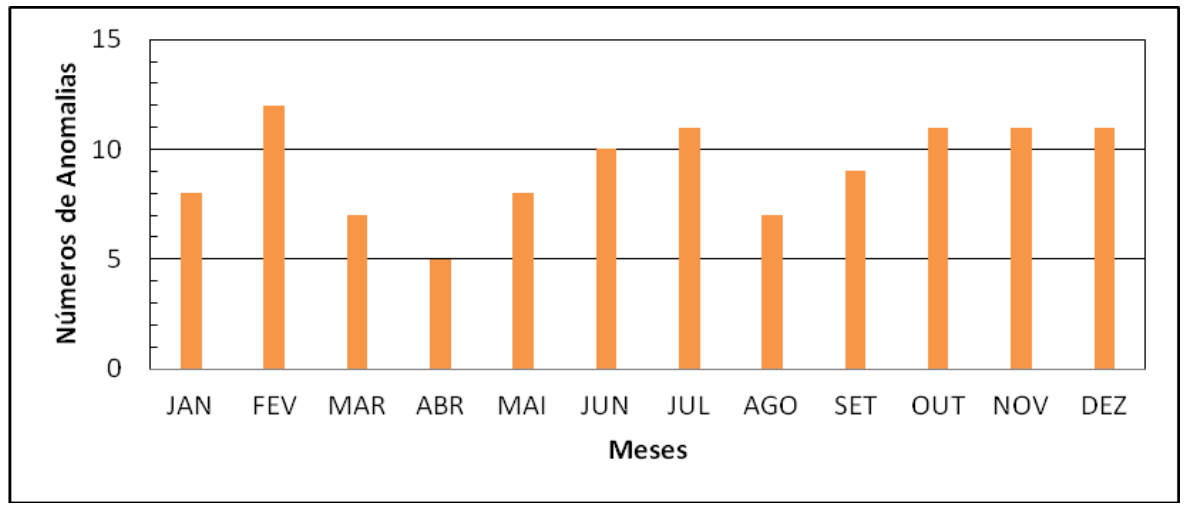

Gráfico 4- Número de ocorrências mensais das anomalias térmicas em Patos, 2010 a 2014. Fonte: Estação Meteorológica de Patos/INMET, 2015

O gráfico 5 mostra a distribuição mensal das anomalias quanto à duração. $\mathrm{O}$ mês de novembro é o de maior número de ocorrências de anomalias $\geq 5$ dias (6 ocorrências), seguido dos meses de setembro, outubro, dezembro, janeiro e fevereiro (ambos meses com 5 ocorrências). Por outro lado, os menores registros de anomalia $\geq 5$ dias encontram-se nos meses de abril, maio e junho.

Os meses de fevereiro, junho e julho são aqueles com uma maior quantidade de ocorrências de anomalias com duração de 3 dias. Com relação às anomalias de 4 dias, os meses de setembro, outubro e dezembro são os que registram o maior número de ocorrências . 


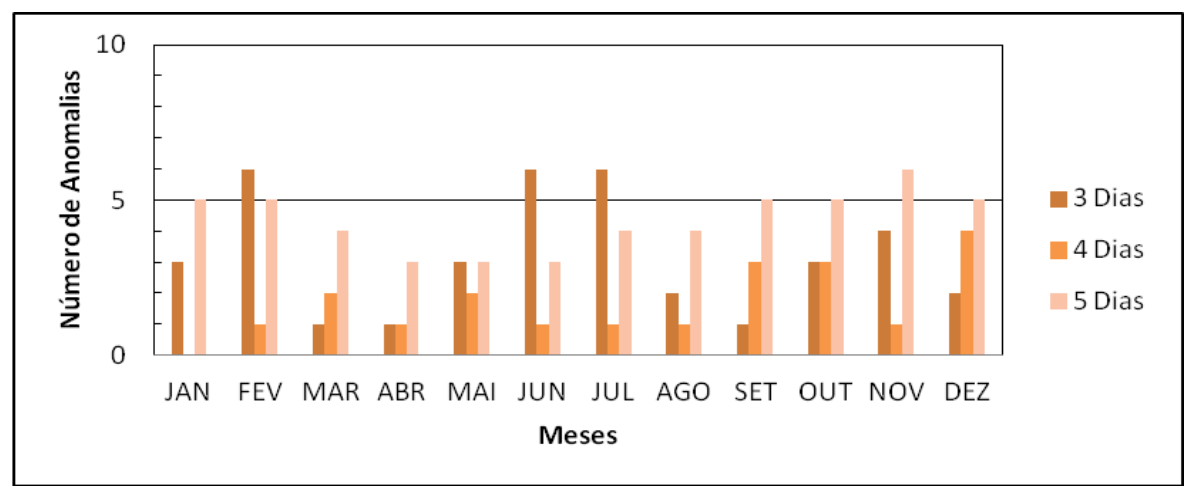

Gráfico 5 - Número de ocorrências mensais por comprimento das anomalias térmicas em Patos, 2010 a 2014 . Fonte: Estação Meteorológica de Patos/INMET, 2015

\section{3 - Classificação dos períodos de calor forte}

Após a identificação e classificação das anomalias térmicas em escala anual, mensal e sazonal, julgou-se necessário revelar as anomalias de maior gravidade térmica da série em uma escala de curto tempo, isto é, em escala diária. Assim, elencaram-se os maiores períodos de calor forte (de maior intensidade e amplitude térmica) registrados na série das anomalias das temperaturas máximas do ar do período de 2010 a 2014 na cidade de Patos.

A tabela 1 mostra a classificação dos dez maiores eventos térmicos da série, onde foram classificados quanto ao maior valor de intensidade térmica, ou seja, o pico da anomalia térmica positiva. Na tabela 1 também consta a duração das anomalias com sua data de ocorrência e seus valores de amplitude térmica.

Tabela 1 - Classificação dos dez maiores períodos de calor forte em Patos, 2010 a 2014

\begin{tabular}{|c|c|c|c|}
\hline \multirow[t]{2}{*}{ CLASSIFICAÇÃO } & \multicolumn{3}{|c|}{ PERIODOS DE CALOR FORTE } \\
\hline & DURAÇAO & INTENSIDADE & AMPLITUDE \\
\hline $1^{0}$ & $\begin{array}{c}20 \text { dias } \\
\text { 1 a } 20 / 02 / 2013\end{array}$ & $\begin{array}{c}4,2 \\
17 / 02 / 2013\end{array}$ & 3,5 \\
\hline $2^{0}$ & $\begin{array}{c}7 \text { dias } \\
22 \text { a } 28 / 02 / 2013\end{array}$ & $\begin{array}{c}4,2 \\
27 / 02 / 2013\end{array}$ & 3,1 \\
\hline $3^{\circ}$ & $\begin{array}{c}16 \text { dias } \\
14 \text { a } 31 / 05 / 2010\end{array}$ & $\begin{array}{c}4,1 \\
29 / 05 / 2010\end{array}$ & 3,5 \\
\hline $4^{0}$ & $\begin{array}{c}12 \text { dias } \\
19 \text { a } 31 / 01 / 2013\end{array}$ & $\begin{array}{c}4,1 \\
20 / 01 / 2013\end{array}$ & 3,5 \\
\hline $5^{\circ}$ & $\begin{array}{c}30 \text { dias } \\
\text { 1 a } 30 / 04 / 2012\end{array}$ & $\begin{array}{c}4 \\
23 / 04 / 2012\end{array}$ & 3,5 \\
\hline $6^{\circ}$ & $\begin{array}{c}19 \text { dias } \\
\text { 1 a } 19 / 05 / 2012\end{array}$ & $\begin{array}{c}3,9 \\
02 / 05 / 2012\end{array}$ & 3,7 \\
\hline $7^{\circ}$ & $\begin{array}{c}4 \text { dias } \\
10 \text { a } 13 / 02 / 2014\end{array}$ & $\begin{array}{c}3,9 \\
13 / 02 / 2014\end{array}$ & 3,6 \\
\hline $8^{\circ}$ & $\begin{array}{c}21 \text { dias } \\
\text { 1 a } 20 / 03 / 2010\end{array}$ & $\begin{array}{c}3,9 \\
18 / 03 / 2010\end{array}$ & 3,1 \\
\hline $9^{\circ}$ & $\begin{array}{c}4 \text { dias } \\
21 \text { a } 24 / 06 / 2012\end{array}$ & $\begin{array}{c}3,7 \\
21 / 06 / 2012\end{array}$ & 3 \\
\hline $10^{\circ}$ & $\begin{array}{c}3 \text { dias } \\
7 \text { a } 9 / 02 / 2012\end{array}$ & $\begin{array}{c}3,6 \\
08 / 02 / 2012\end{array}$ & 3,4 \\
\hline
\end{tabular}


Dos dez eventos de calor forte, quatro ocorreram no ano de 2012 e três no ano de 2013. Cabe mencionar que esses anos foram considerados muitos secos em Patos $(219,7 \mathrm{~mm}$ em 2012 e 427,0 mm em 2013), de acordo com os dados de precipitação do DBMET/INMET (2015). Quanto à sazonalidade dos eventos oito ocorreram nos meses da estação chuvosa. Nota-se também que dos dez eventos, sete possuem duração $\geq 5$ dias. O mês de fevereiro possui a maior quantidade de eventos (4 ocorrências). Não obstante, há três registros de eventos com duração inferior a $\geq 5$ dias, dois deles ocupam as últimas posições, conforme mostra a tabela 1.

Os períodos de calor forte da série apresentaram valores de intensidade térmica entre $4,2^{\circ} \mathrm{C}$ a $3,6^{\circ} \mathrm{C}$ e valores de amplitude térmica entre $3,7^{\circ} \mathrm{C}$ a $3^{\circ} \mathrm{C}$. O evento mais excepcional da série foi registrado entre os dias 1 e 20 de fevereiro de 2013, trata-se, portanto de uma anomalia com duração de 20 dias, com pico térmico de $4,2^{\circ} \mathrm{C}$ e amplitude térmica de $3,5^{\circ} \mathrm{C}$.

\section{CONSIDERAÇÕES FINAIS}

Na cidade de Patos, entre 2010 e 2014, registrou-se um total de 110 anomalias de temperaturas máximas do ar. Predominantemente as anomalias possuem duração $\geq 5$ dias na cidade, e os períodos de calor mais forte também ocorrem nesse intervalo de tempo. Esse fato revela que a população está em constante risco a eventos de calor forte, mesmo no período mais chuvoso do ano, visto que, dos dez maiores registros de calor, oito concentram-se na estação chuvosa.

Este ensaio sobre o comportamento anômalo das temperaturas máximas do ar poderá contribuir com outros estudos sobre o clima local de Patos na perspectiva do conforto térmico e do estado de saúde da população, além de estudos no campo da adaptação climática e de gestão dos riscos. Por fim, cabe considerar que o período investigado sobre as anomalias na cidade foi muito reduzido, ou seja, de 2010 a 2014, e esse coincide com o período de estiagem registrado na região semiárida do Nordeste.

\section{REFERÊNCIAS}

BDMEP/INMET. Banco de Dados Meteorológicos para Ensino e Pesquisa. Instituto Nacional de Meteorologia. Disponível em: http://www.inmet.gov.br/portal/index.php?r=bdmep/bdmephttp://www.inmet.gov.br/portal/index.ph $\mathrm{p}$ ?r=bdmep/bdmep Acesso em: 06 ago. 2015.

CAVAlCANTE, G. P.; MOURA, M. O. Episódios de Calor Extremo na cidade de João Pessoa, Paraíba, Brasil. Anais do VII Workshop de Mudanças Climáticas e Recursos Hídricos do Estado de Pernambuco e IV Workshop sobre Mudanças Climáticas e Biodiversidade, p. 272294. UFPE, ITEP, Recife, 2015. CD-ROM. 
CAVAlCANTE, V.L.U. A Centralidade da Cidade de Patos-PB : um estudo a partir de arranjos espaciais. (Dissertação de Mestrado). João Pessoa: Programa de Pós-Graduação em Geografia, 2008. 115p

FIRPO, M. A. F. Climatologia das ondas de calor e de calor para o Rio Grande do Sul e sua relação com El Niño e La Niña. (Dissertação de Mestrado). Pelotas/RS: Programa de PósGraduação em Meteorologia, 2008. 119p.

JIMÉNEZ, J. D; GIL, C. L; HERRERA, R. G.Impacto de las temperaturas extremas enlasalud pública: futuras actuaciones.Revista EspanõlaSalud Pública, n.2, v.79, p.145-157, Mar/Abr, 2005. Disponível em: http:// www.scielosp.org. Acesso em: 09 mai. 2011.

MOURA, M. O. O clima urbano de Fortaleza sob o nível do campo térmico. (Dissertação de Mestrado). Fortaleza: Programa de Pós- Graduação em Geografia/UFC, 2008. 318p

MOURA, M.O. Anomalias das temperaturas extremas do ar em Fortaleza, Ceará, Brasil. Revista Brasileira de Geografia Física, Recife, v. 08, n.06, p. 1588-1600, 2015. Disponível em: http://www.revista.ufpe.br/rbgfe/index.php/revista/article/view/1535/882 Acesso em: 21 jan. 2016.

TRIOLA, M. F. Introdução à estatística. 10 ed. Rio de Janeiro: Livros Técnicos e Científicos Editora S.A., 2008. 696p.

RUSTICUCCI, M. M; BARRUCAND, M. Climatología de temperaturas extremas enla Argentinavariabilidad temporal y regional. Meteorologica, vol. 26, p.85-101, 2001. Disponível em: http://www.cenamet.org.ar/meteorologica. Acesso em: 24 mar. 2011.

RUSTICUCCI, M. M.; VARGAS, W.M. Interannual variability of temperature spells over Argentina. Atmósfera, v.14, n.2, p. 75-86, 2001. Disponível em: http://www.catalogoderevistas.unam.mx/pt/interiores/atmosfera Acesso em: 24 mar.2011.

SILVA, L. L. Precipitações Pluviais da Pré-Estação Chuvosa no Período Chuvoso e suas Influências na Produtividade Agrícola da Paraíba. (Dissertação de Mestrado). Campina Grande: Programa de Pós-Graduação em Meteorologia/UFCG, 2007. 114p.

Recebido em: 14/08/2016

Aceito para publicação em: 01/10/2016 